\title{
Soroprevalencia de anticorpos anti-Anaplasma marginale em propriedades de agricultura familiar no munício de Realeza, estado do Paraná, Brasil
}

Lisangela Veiga Trevisan;, Regiane Figueredo Ghisleri, Anderson Beltrame, Michel Fritz, Diego Kozerski, Alexandra Lays Petry, Julyana Paula da Silva, Lucas Vieira Barbosa de Queiroz, Ana Aline Kolcheski, Fagner Luiz da Costa Freitas

Universidade Federal da Fronteira Sul (UFFS), Realeza, PR, Brasil

*Autor correspondente

e-mail: lisatrevisanmv@gmail.com

\section{Resumo}

No município de Realeza/PR, a atividade leiteira é desenvolvida principalmente pela agricultura familiar, onde a maioria dos produtores desconhece a cadeia epidemiológica dos patógenos, assim como os métodos de higienização ou profilaxia, mantendo atitudes que acabam favorecendo a infecção do seu rebanho. Dentre as principais doenças que acometem os bovinos, destaca-se a anaplasmose, causada pela hemobacteria Anaplasma marginale. 0 agente infeccioso ocasiona sinais clínicos pouco específicos, tais como: anemia, febre, apatia e abortos que sendo transmitida por moscas hematofagas e carrapatos e fômites contaminados com o patógeno. A pesquisa avaliou a soroprevalência de anticorpos anti-A. marginale em vacas com aptidão leiteira, em fase de lactação, oriundas de 56 propriedades de agricultura familiar pertencentes ao município de Realeza/PR. 0 trabalho foi aprovado pela Comissão de Ética de Uso de Animais da Universidade Federal da Fronteira Sul , sob o protocolo 23205.004368/2016-11, sendo pesquisados 389 animais oriundos de 56 propriedades de agricultura familiar. Após a contenção do animal, realizou-se coleta de sangue pela veia coccígea por meio de agulhas individuais e tubos com vácuo sem anticoagulante. Após a coleta, o material biológico foi encaminhado no interior de caixas de isopor com gelo ao Laboratório de Saúde Única da Universidade Federal da Fronteira Sul, Campus Realeza/PR, onde soro foi submetido à técnica de Ensaio Imunoenzimático Indireto (ELISA) para detecção de anticorpos IgG anti-A. marginale, utilizando a diluição de 1:400. Os dados evidenciaram $82,1 \%$ de propriedades soropositivas e 44,9\% de animais reagentes para anticorpos anti- $A$. marginale, demonstrando a presença de instabilidade enzoótica para anaplasmose no município de Realeza. A prevalência de anticorpos anti- $A$. marginale obtida no presente estudo foi inferior aos dados observados em outras regiões do estado do Paraná, porém demonstra um aumento de animais soropositivos quando comparado com pesquisas desenvolvidas no mesmo território no ano de 2015. 
Trabalhos de pesquisa e extensão são necessários para dimensionar a distribuição do agente infeccioso no sudoeste paranaense, principalmente em áreas de fronteira seca, onde a fiscalização de patógenos é insuficiente devido à grande extensão terriotrial e reduzido número de fiscais. 